\title{
Relationships between kiwifruit bacterial canker disease and kiwifruit productivity
}

\author{
K.J. Froud ${ }^{1}$, N. Cogger ${ }^{1}$ and R.M. Beresford ${ }^{2}$ \\ ${ }^{1}$ Massey University, Private Bag 11-222, Palmerston North 4442, New Zealand \\ ${ }^{2}$ Plant E Food Research, Private Bag 92169, Auckland Mail Centre, Auckland 1142, \\ New Zealand \\ Corresponding author: karyn.froud@orcon.net.nz
}

\begin{abstract}
Bacterial canker disease, caused by a virulent strain of Pseudomonas syringae pv. actinidiae (Psa-V) has affected kiwifruit vines in New Zealand since 2010. This study investigated the association of Psa- $\mathrm{V}$ with productivity within 'Hayward' and 'Hort16A' varieties. Psa-V infection status and date of diagnosis for 3,309 infected orchards were provided by Kiwifruit Vine Health, while Zespri provided productivity data. Linear regression models were constructed to determine the relationship between production and Psa-V infection in 'Hayward' and 'Hort16A' orchards. Results showed a significant relationship between the numbers of weeks Psa-V was detected in 'Hort16A' orchards and a reduction in productivity. This was likely due to the removal of Hort16A vines or productive areas of canopy in response to the presence of severe symptoms within an orchard. A similar significant relationship was also found in 'Hayward' orchards, although the reduction in productivity was smaller and took longer to develop than in 'Hort16A'.
\end{abstract}

Keywords Actinidia chinensis, Actinidia deliciosa, Pseudomonas syringae pv. actinidiae, Psa, linear regression, production, 'Hayward', 'Hort16A', retrospective, cohort, observational study.

\section{INTRODUCTION}

On 5 November 2010 a virulent strain of Pseudomonas syringae pv. actinidiae (Psa-V), which causes bacterial canker in kiwifruit, was first detected in New Zealand kiwifruit (Everett et al. 2011). Psa-V causes leaf spotting, shoot and cane dieback and stem cankers and in severe cases the whole vine is affected leading to death and/or removal from the orchard. It has had a major impact on the 'Hort16A' variety (Actinidia chinensis) with reports from industry of removal of diseased canopy and vines, and a lesser effect on 'Hayward' (Actinidia deliciosa) to date with very few reports of canopy removal (G. Clark, Zespri International Ltd., personal communication).
The export value of the kiwifruit industry to New Zealand in 2012 was $\$ 1.0457$ billion and kiwifruit is the second largest horticultural export from New Zealand (Aitken \& Hewett 2012). The cost of Psa-V to the New Zealand kiwifruit industry was estimated in 2012 to be approximately $\$ 126$ million (Greer \& Saunders 2012). In addition, Greer \& Saunders (2012) estimated an on-going cost of Psa-V to New Zealand of $\$ 740$ to $\$ 885$ million over the next 15 years. It has been well reported that Psa-V is having an impact on the viability of 'Hort $16 \mathrm{~A}$ ' vines both in New Zealand and internationally (Ferrante \& Scortichini 2009; Everett et al. 2011; Ferrante et al. 2012; 
Greer \& Saunders 2012; Vanneste 2012). However, the effect of Psa-V presence on productivity in commercial 'Hort16A' and 'Hayward' orchards has not been quantified. A key assumption in Greer \& Saunders's (2012) report is that productivity in green varieties, most of which are 'Hayward' vines, will remain unchanged in Psa-V infected regions. There is mounting evidence that challenges the assumptions with regard to Psa-V impacts on 'Hayward' vines. Firstly, leaf spotting, which is considered a 'mild' symptom of exposure to Psa-V inoculum, is now common in 'Hayward' orchards within Psa-V infected regions. Secondly, reports of more severe Psa-V associated symptoms such as leaf wilt and shoot or cane dieback were being received by industry in the spring of 2011 from concerned 'Hayward' growers. It was unknown what, if any, impact Psa-V was having on 'Hayward' productivity in New Zealand, although severe symptoms such as shoot wilt, cane dieback and cankers have been observed in Italy on this variety (Ferrante et al. 2012).

The aim of this research was to describe the relationship between the presence of $\mathrm{Psa}-\mathrm{V}$ in commercial kiwifruit orchards and productivity of 'Hort16A' and 'Hayward' varieties of kiwifruit.

\section{MATERIALS AND METHODS \\ Data collection}

A dataset containing the Psa-V infection status of individual orchards and, for those that were infected, the date of detection, was provided by Kiwifruit Vine Health (KVH). The method used to determine infection status changed during the outbreak, from cases being defined as orchards with Psa-V confirmed by diagnostic testing early on to cases defined as either orchards with Psa-V confirmed by diagnostic testing as previously, or, through the observation of the more severe visual signs of disease confirmed by a technical representative of Zespri, KVH, a packhouse or similar industry body. The signs of disease considered evidence of Psa-V during the growing season were blackened canes or shoots with dieback and/or stem wilting. While in winter, signs of disease were bleeding cankers with or without red exudate. Both methods of Psa-V identification were considered to be cases in the current study. The date of a positive diagnostic test or the date clear visual signs of disease were reported was recorded in the database as the date of confirmed infection.

Production data for 'Hort16A' and 'Hayward' kiwifruit, picked in the 2011 and 2012 seasons, were provided by Zespri International Ltd (Zespri) as gross tray equivalents (i.e. volumes of fruit prior to grading) and productive hectares, for each variety.

\section{Classifying disease status for each orchard}

The disease status of each orchard was described with three variables: (1) a binary variable, 'Psa status 2011', with a value of one if Psa-V had been detected by the end of the 2010/11 harvest and zero if it had not, (2) a binary variable, 'Psa status 2012', that was coded one if Psa-V had been detected by the end of the 2011/12 harvest (including all those where 'Psa status 2011' was one) and zero if it had not, and (3) a continuous variable 'Weeks since detection' that described the number of weeks between the date Psa- $\mathrm{V}$ was first detected and 2011/12 harvest date. For those orchards where a single variety was harvested over more than one day, the end point for weeks since detection was the median harvest date. For orchards where Psa-V had never been detected, or was not detected until after harvest ended, the 'weeks since detection' was zero.

\section{Data management, validation and analysis}

Data extracted from KVH and Zespri databases were merged in MS Access and then split into one data set for 'Hort16A' and one for 'Hayward'. MS Excel and ' $R$ ' freeware statistical package version 3.0.1 (R Core Team 2013) were then used to assess the completeness and validity of the aggregated data set. Continuous variables were checked for extreme values and categorical variables were checked using one- and two-way contingency tables. Where appropriate, missing or unusual values were checked against other data sources, or with the database managers at KVH or Zespri.

Data analysis was conducted using ' $R$ ' statistical package version 3.0.1 (R Core Team 2013) and the level of statistical significance was set at $\mathrm{P}<0.05$. Data for 'Hort $16 \mathrm{~A}$ ' and for 'Hayward' 
were analysed separately. Initially the number and percentage of orchards that were infected at the end of the 2010/11 and 2011/12 growing seasons was determined. Frequency histograms of productivity, measured in tray equivalents per hectare (te/ha), in the 2010/11 and 2011/12 seasons were created and appropriate summary statistics calculated. Separate box plots were produced to visualise the relationship between production in each season and Psa-V status at the end of harvest for the season. For each season the significance of the relationship between productivity and Psa-V status was assessed using a two-sample t-test.

For the 2011/2012 season a scatter plot of production by weeks since Psa-V was detected was created and a lowess smoothing line added to visualise the relationship. A simple linear regression model was created to quantify the relationship between days since detection and production, and a quadratic term for the days since detection was also added to the model if the scatter plot indicated that the relationship was non-linear. The collective significance of predictors in the model was assessed using the F-test statistic and the significance of each regression coefficient was assessed using the t-test.

\section{RESULTS}

\section{'Hort16A'}

There were 884 orchards with 'Hort16A' kiwifruit. In total, 24 observations were removed from the dataset because both the 2011 and 2012 production data $(n=23)$ or the Psa-V status were missing $(n=1)$. In addition, 2012 production data were missing from a further 121 orchards, 114 of which $(94.2 \%)$ were confirmed Psa-V positive prior to the start of the 2012 'Hort 16A' harvest period (16/03/12). These 121 observations were retained in the dataset, but only contributed to analysis of the 2011 season as they had missing values for the 2012 season. The final 'Hort16A' data set contained data from 860 orchards.

At the end of the 2010/11 season Psa-V had been detected in 30 'Hort16A' orchards, all in the Te Puke region. By the end of the 2011/12 season a further eight regions growing kiwifruit were affected and Psa-V had been detected on 414 'Hort16A' orchards, 120 of which (29\%) were no longer commercially producing 'Hort 16A' kiwifruit. Of the original 30 orchards that became infected in 2010/11 only three were still commercially producing 'Hort16A' kiwifruit in 2011/12.

In the 2010/11 season 'Hort16A' mean productivity was $12,190 \pm 4,084(\mathrm{SD})$ te/ha and there was no significant difference in productivity between those orchards with Psa-V and those without $(\mathrm{P}=0.88)$. In the $2011 / 12$ season the mean productivity was $11,090 \pm 4,640$ (SD) te/ha. In contrast with the first season, however, in the 2011/12 season there was a significant decrease in productivity in those orchards in which Psa-V had been detected $(\mathrm{P}<0.001)$ (Table 1$)$.

When Psa-V status was expressed in terms of weeks since detection there was evidence of a non-linear relationship between disease status and 2012 productivity as shown by the lowess line of best fit in Figure 1. This observation was supported by the simple linear regression model in which a quadratic term for weeks since detection was significantly associated with productivity (Table 2 ).

\section{'Hayward'}

There were 2,953 orchards with 'Hayward' kiwifruit. In total, 354 observations were removed from the dataset because 2012 production data were missing $(n=326), 2011$ production data were missing $(n=25)$ or because of obvious data entry errors $(n=3)$. In the case of data entry errors the production recorded for 2012 was well in excess of the industry best practice productivity. Of the orchards with missing 2012 production data only 41/326 (13\%) were confirmed Psa-V positive prior to the start of the 2012 'Hayward' harvest period (28/3/12). The final data set contained 2,599 orchards with 'Hayward' kiwifruit. There were $472(14.3 \%)$ orchards with both 'Hort16A' and 'Hayward' varieties grown on them.

At the end of the 2010/11 season Psa-V had only been detected on 71 'Hayward' orchards in a single region (Te Puke). By the end of the 2011/12 season this number had increased to 939 orchards over nine regions. 
Table 1 Productivity in tray equivalents per hectare (te/ha) for orchards with different Psa-V status at the end of the 2010/11 and 2011/12 growing seasons for 'Hort16A' kiwifruit.

\begin{tabular}{lccccccc}
\hline & \multicolumn{3}{c}{ Mean productivity (SD) } & \multicolumn{2}{c}{ Number of orchards } \\
\cline { 2 - 4 } Season & All orchards & $\begin{array}{c}\text { Psa-V } \\
\text { negative }\end{array}$ & $\begin{array}{c}\text { Psa-V } \\
\text { positive }\end{array}$ & P-value & & Psa-V & \multicolumn{2}{c}{$\begin{array}{c}\text { Psa-V } \\
\text { negative }\end{array}$} & positive \\
\hline $2010 / 11$ & $12190(4084)$ & $12201(4074)$ & $12303(3812)$ & 0.88 & 860 & 30 \\
$2011 / 12$ & $11090(4640)$ & $11733(4423)$ & $10155(4780)$ & $<0.001$ & 445 & 294 \\
\hline
\end{tabular}

Table 2 Simple linear regression model describing the relationship between weeks since detection of Psa-V and productivity, measured in tray equivalents per ha (te/ha) in 2012. Data are from 736 separate 'Hort16A' orchards which were still in production. The model has 733 degrees of freedom with a residual standard error of 4484 and an adjusted R-squared value of 0.066.

\begin{tabular}{lcccc}
\hline Variable & Value & $\begin{array}{c}\text { Standard } \\
\text { error }\end{array}$ & t-value & P-value \\
\hline $\begin{array}{l}\text { Intercept } \\
\begin{array}{l}\text { Time since Psa-V detected } \\
\text { (weeks, centred on the mean) }\end{array}\end{array}$ & $11,576.3^{1}$ & 271.07 & 42.71 & $<0.0001$ \\
$\begin{array}{l}\text { Time since Psa-V detected-squared } \\
\text { (weeks squared, centred on the mean) }\end{array}$ & $-49.3^{2}$ & 17.78 & -2.77 & 0.006 \\
\hline
\end{tabular}

${ }^{1}$ Interpretation - The average productivity was 11,576 te/ha in orchards that had not detected Psa-V by the end of the 2012 growing season (i.e. when time since Psa-V detected is zero).

${ }^{2}$ Interpretation - The relationship between time since Psa-V detected and productivity is not linear and productivity decreases at a faster rate over time.

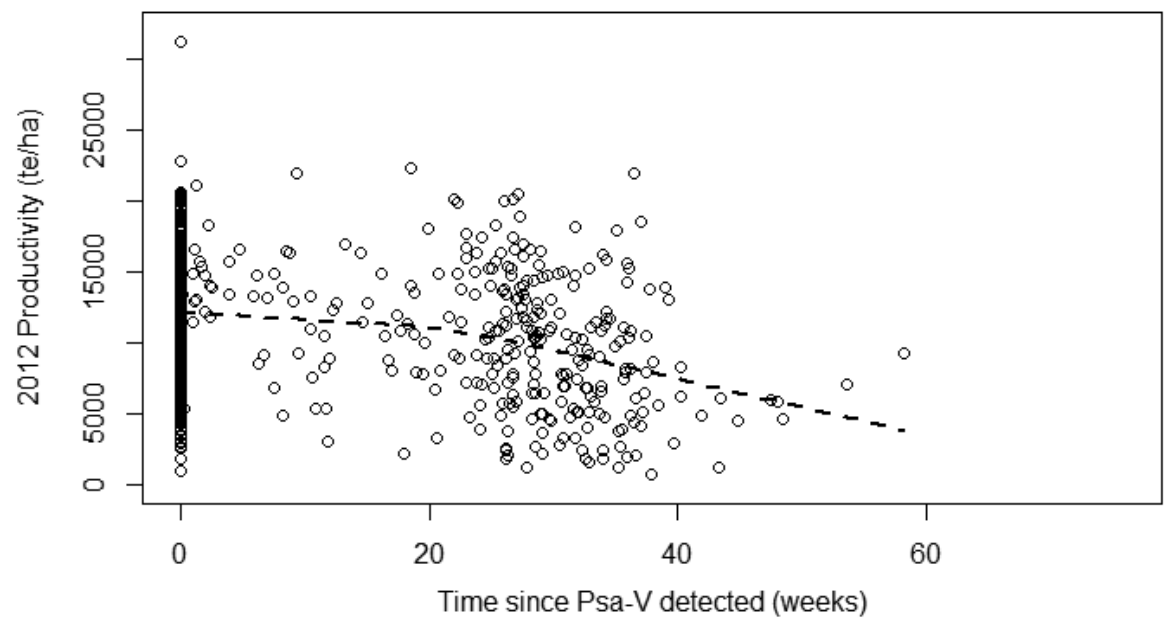

Figure 1 Productivity (tray equivalents per ha) of 'Hort16A' kiwifruit in 2012 in relation to the number of weeks since Psa-V was detected from 736 separate orchards with 'Hort16A' kiwifruit remaining in production during the 2011/12 growing season. Dashed line is the lowess line of best fit and shows the non-linear relationship between weeks since Psa-V was detected and productivity. Bunching at 0 weeks is due to a large group of uninfected orchards. There is also a seasonal effect apparent showing the large increase in infected orchards in spring 2011. 
'Hayward' mean productivity for 2010/11 was $8,775 \pm 2,551$ (SD) te/ha with no significant difference in productivity between orchards with Psa-V and those without $(\mathrm{P}=0.30)$ (Table 3$)$. In $2011 / 12$, mean productivity across all regions was $8,096 \pm 2,540(\mathrm{SD})$ te/ha, and there was a significantly $(\mathrm{P}<0.001)$ higher productivity in those orchards in which Psa-V had been detected compared to those without Psa-V detected (Table $3)$. This higher productivity is related to regional differences in both productivity and disease prevalence and will be explored in the discussion.

When Psa-V status was expressed in terms of weeks since detection there was evidence of a nonlinear relationship between disease status and productivity as shown by the lowess line of best fit in Figure 2. This observation was supported by the linear regression model in which a quadratic term for weeks since detection was significantly associated with productivity (Table 4).

\section{DISCUSSION}

The present results support industry reports that there is a direct and significant relationship between presence of Psa-V in a 'Hort16A' orchard and a reduction in productivity. Only three orchards within the dataset harvested 'Hort16A' kiwifruit for a second season following Psa-V infection. A further 114 Psa-V infected 'Hort16A' orchards ceased producing Hort16A fruit in the 2012 season. This was largely due to growers removing productive Hort16A canopies and grafting over to new Gold varieties of greater Psa tolerance (G. Clark, Zespri International Ltd., personal communication). The impact of Psa-V over time on 'Hort16A' production systems showed a gradual reduction in productivity for the first 25 weeks and an increasing reduction in productivity beyond 25 weeks after first detection.

The apparent increase in mean productivity of infected 'Hayward' blocks compared to the mean of un-infected vines was an artefact of the study design and due to the regional differences between productivity and disease prevalence, as the disease was most prevalent in regions with the highest productivity. This artefact was particularly evident in the 'Hayward variety as the effect of the disease on productivity was

Table 3 Productivity in tray equivalents per hectare (te/ha) for orchards with different Psa-V status at the end of the 2010/11 and 2011/12 growing seasons for 'Hayward' kiwifruit.

\begin{tabular}{lccccccc}
\hline & \multicolumn{3}{c}{ Mean productivity $(\mathrm{SD})$} & \multicolumn{2}{c}{ Number of orchards } \\
\cline { 2 - 4 } Season & All orchards & $\begin{array}{c}\text { Psa-V } \\
\text { negative }\end{array}$ & $\begin{array}{c}\text { Psa-V } \\
\text { positive }\end{array}$ & P-value & & Psa-V & \multicolumn{2}{c}{ Psa-V } \\
negative & positive \\
\hline $2010 / 11$ & $8775(2551)$ & $8766(2557)$ & $9085(2327)$ & 0.30 & 2528 & 71 \\
$2011 / 12$ & $8096(2540)$ & $7872(2640)$ & $8495(2302)$ & $<0.001$ & 1660 & 939 \\
\hline
\end{tabular}

Table 4 Simple linear regression model describing the relationship between weeks since detection of Psa-V and productivity, measured in tray equivalents per ha (te/ha) in 2012. Data are from 2,599 separate orchards with 'Hayward' production. The model has 2596 degrees of freedom with a residual standard error of 2518 and an adjusted R-squared value of 0.018 .

\begin{tabular}{lccrc}
\hline Variable & Co-efficient & Standard error & t-value & P-value \\
\hline Intercept & $7888^{1}$ & 60.38 & 130.63 & $<.0001$ \\
Time since Psa-V detected (week) & $53^{2}$ & 7.56 & 6.92 & $<.0001$ \\
Time since Psa-V detected-squared & $-0.89^{2}$ & 0.15 & -5.89 & $<.0001$ \\
\hline
\end{tabular}

${ }^{1}$ Interpretation - The average productivity was 7,888 te/ha in orchards that had not detected Psa-V by the end of the 2012 growing season (i.e. when time since Psa-V detected is zero).

${ }^{2}$ Interpretation - The relationship between time since Psa-V detected on the orchard and productivity is not linear and decreases at a faster rate over time. 


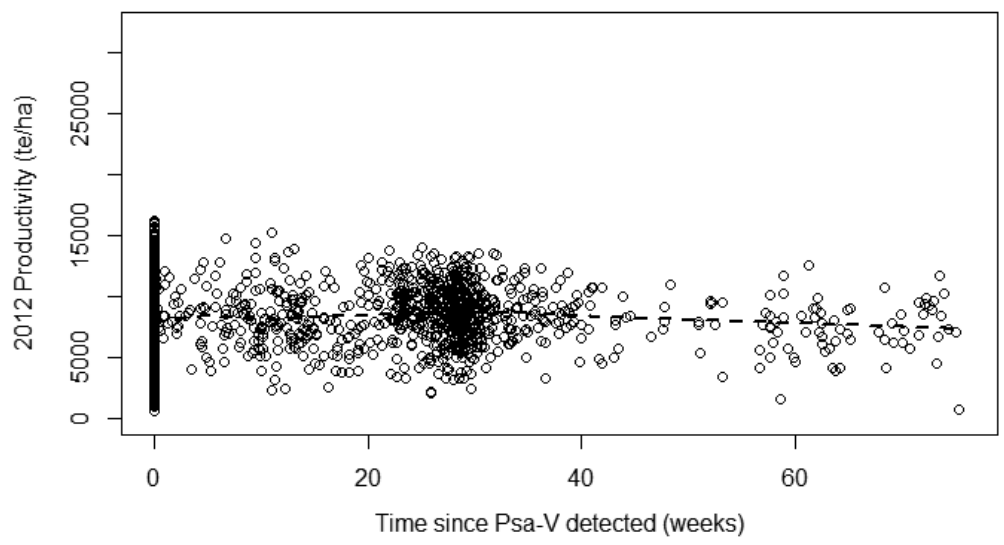

Figure 2 Productivity (tray equivalents per ha) of 'Hayward' kiwifruit in 2012 in relation to the number of weeks since Psa-V was detected from 2,599 separate orchards with 'Hayward' kiwifruit in production during the 2011/12 growing season. Dashed line is the lowess line of best fit and shows the non-linear relationship between weeks since Psa-V was detected and productivity. Bunching at 0 weeks is due to a large group of uninfected orchards. There is also a seasonal effect apparent showing the large increase in infected orchards in spring 2011.

relatively low. In the 'Hort16A' orchards the effect of the disease and removal of vines due to disease on productivity was higher and regional differences were not sufficient to distort the negative relationship of Psa-V and productivity. In order to address this, the focus will be on the relationship between weeks since Psa-V was detected and productivity, with region being included as a confounding factor in any future multivariable analysis.

There was also a significant relationship between weeks since Psa-V was first detected and productivity in commercial 'Hayward' orchards. The present study showed a time delay between detection and any reduction in productivity in 'Hayward' to more than 35 weeks and the reduction in productivity beyond 35 weeks was quite small. In addition infected growers were able to maintain commercial production beyond one season in comparison with 'Hort16A'. A possible non-causal reason for the observed time lag prior to a drop in productivity in 'Hayward' is that the outcome variable, weeks since detection, was based on the date that Psa-V was first confirmed in the whole orchard. Therefore, the first detection may have been in another variety (e.g. 'Hort16A') on the same orchard, well before sufficient numbers of 'Hayward' vines were infected for Psa-V to affect 'Hayward' productivity. The change in diagnostic testing methods to define a case as the outbreak progressed is likely to account for some of the variability in the linear regression and scatterplot results. The data used in this analysis were not from a randomised trial so the significant (non-linear) association between Psa-V and productivity may have been confounded, or otherwise altered, by a number of factors being present (Dohoo et al. 2010). In particular, as mentioned, region has a significant impact on both the time since an orchard was detected with Psa-V as well as being a proxy for all of the soil and weather differences that affect productivity between regions. The other important factor that may influence the relationship between weeks detected and 2012 productivity is the change in spray practices in infected orchards where use of Psa-V protectant sprays is likely to reduce the impact of Psa-V on productivity.

This relationship between region, spray applications and a range of other potential confounders and productivity will be further explored in future research on the 'Hayward' data where it will be possible to assess confounding by 
constructing multivariable models to examine the relationship between the outcome, study factor and confounders. This will enable us to estimate the effect of the study factor while 'controlling' for other variables (Dohoo et al. 2010).

It would be possible to model the impact of Psa-V on 'Hort16A' while taking account of all of the other factors that influence productivity, but it is unnecessary to do so as the industry has been taking management action to remove susceptible canopies and re-graft to more tolerant Gold varieties. The Kiwifruit Vine Health board passed a resolution in 2012 calling on Zespri and the industry to help facilitate the removal and replacement of 'Hort16A' that is infected or is at high risk of infection with Psa-V and Zespri has included this in their recovery pathway (Greer \& Saunders 2012). The present study supports the industries' decision to remove highly susceptible varieties such as 'Hort16A' in favour of new, more tolerant varieties. The results indicate that removal of highly susceptible vines such as 'Hort16A' should occur within 5-12 months of detection of Psa-V in an orchard. The results for the 'Hayward' variety show a delayed but significant small reduction in productivity for every week since Psa-V detection. Completion of the multivariable modelling research will give greater insight into the impact of Psa- $\mathrm{V}$ on 'Hayward' productivity.

\section{ACKNOWLEDGEMENTS}

We would like to thank KVH for provision of Psa data and Zespri for the provision of productivity and spray data. This project was funded by the Kiwifruit Vine Health and Zespri Psa research programme under contract number V11348.

\section{REFERENCES}

Aitken AG, Hewett EW 2012. Fresh Facts: New Zealand Horticulture 2012. Fresh Facts 14. Plant \& Food Research and Horticulture New Zealand, Auckland, New Zealand. 19 p.

Dohoo IR, Martin W, Stryhn H 2010. Veterinary epidemiologic research. University of Prince Edward Island, Charlottetown, P.E.I., Canada. $865 \mathrm{p}$.

Everett KR, Taylor RK, Romberg MK, ReesGeorge J, Fullerton RA, Vanneste JL, Manning MA 2011. First report of Pseudomonas syringae pv. actinidiae causing kiwifruit bacterial canker in New Zealand. Australasian Plant Disease Notes 6: 67-71.

Ferrante P, Scortichini M 2009. Identification of Pseudomonas syringae pv. actinidiae as causal agent of bacterial canker of yellow kiwifruit (Actinidia chinensis Planchon) in Central Italy. Journal of Phytopathology 157: 768-770.

Ferrante P, Fiorillo E, Marcelletti S, Marocchi F, Mastroleo M, Simeoni S, Scortichini M 2012. The importance of the main colonization and penetration sites of Pseudomonas syringae pv. actinidiae and prevailing weather conditions in the development of epidemics in yellow kiwifruit, recently observed in central Italy. Journal of Plant Pathology 94: 455-461.

Greer G, Saunders C 2012. The costs of Psa-V to the New Zealand kiwifruit industry and the wider community. Report to Kiwifruit Vine Health. Lincoln University, Christchurch, New Zealand. 75 p.

R Core Team 2013. R: A Language and Environment for Statistical Computing. Foundation for Statistical Computing, Vienna, Austria. URL http://www.R-project.org/.

Vanneste JL 2012. Pseudomonas syringae pv. actinidiae (Psa): a threat to the New Zealand and global kiwifruit industry. New Zealand Journal of Crop and Horticultural Science 40: 265-267. 